\title{
UPAYA PENCEGAHAN DINI DIABETES MELITUS TERHADAP PENINGKATAN PENGETAHUAN SISWA DI SMA NEGERI 1 GOWA
}

\author{
Early Diabetes Mellitus Prevention Efforts Towards The Improvement Of The Knowledge Of Students I \\ n Sma Negeri 1 Gowa
}

\author{
Nurul Muthahara, Masdiana AR, Agusti Fauzia
}

nurulmuthahara1996@gmail.com

\begin{abstract}
Background Diabetes is a chronic metabolic disorder caused by the pancreas not producing enough insulin or the body cannot use insulin that is produced effectively. Research Objectives To improve students' knowledge about efforts to prevent diabetes mellitus through health education. Research Methods This type of research is quantitative. with the research design using an experimental approach. namely quasi-experimental (Quasi experiment) such as pre-post test intervention group and control group. where the design is classified in the Non Randomized PretestPostest design. Control Group Design). Research Results Based on the results of the statistical test (Mc Nemar) which shows that the level of trust (CL.0,95) obtained the value of Exact Sig for two sides of 0,000 $<\alpha=0,05$ reject Ho which means that there are differences in the level of knowledge of students from before and after the intervention. Whereas in $C L=0.95$, the value of Exact Sig for two sides is $0.125>\alpha=0.05$ which accepts Ho which means that there is no difference in students' level of knowledge. Conclusion there is a significant influence of DM early prevention efforts on increasing the knowledge of students of SMAN 1 Gowa Regency as an intervention group. whereas in the control group there was no significant effect of DM early prevention efforts on increasing the knowledge of students of SMAN 3 Gowa Regency.

Keywords: Knowledge. Prevention Efforts. Diabetes Mellitus
\end{abstract}

\section{ABSTRAK}

Diabetes Melitus merupakan penyakit gangguan metabolik menahun akibat pankreas tidak memproduksi cukup insulin atau tubuh tidak dapat menggunakan insulin yang diproduksi secara efektif. Tujuan Penelitian Untuk meningkatkan pengetahuan siswa tentang upaya pencegahan diabetes melitus melalui pendidikan kesehatan. Metode Penelitian Jenis penelitian ini adalah kuantitatif, dengan desain penelitian menggunakan pendekatan Eksperimental, yaitu Eksperimen semu (Quasi eksperimen) seperti pre-post test kelompok intervensi dan kelompok control, dimana rancangannya tergolong dalam rancangan Eksperimen Ulang Non-random (Non Randomized Pretest-Postest with Control Group Design). Hasil Penelitian Berdasarkan hasil dari uji statistic (Mc Nemar) yang menunjukkan bahwa tingkat kepercayaan (CL.0,95) di peroleh nilai Exact Sig untuk dua sisi sebesar $0,000<a=$ 0,05 menolak Ho yang berarti bahwa terdapat perbedaan tingkat pengetahuan siswa dari sebelum dan sesudah dilakukan intervensi. Sedangkan pada $\mathrm{CL}=0,95$ diperoleh nilai Exact Sig untuk dua sisi sebesar 0,125 > $\alpha=0,05$ menerima Ho yang berarti bahwa tidak terdapat perbedaan tingkat pengetahuan siswa. Kesimpulan terdapat pengaruh yang signifikan upaya pencegahan dini DM terhadap peningkatan pengetahuan siswa SMAN 1 Kabupaten Gowa sebagai kelompok intervensi, sedangkan pada kelompok kontrol tidak terdapat pengaruh yang signifikan upaya pencegahan dini DM terhadap peningkatan pengetahuan siswa SMAN 3 Kabupaten Gowa.

Kata Kunci : Pengetahuan, Upaya Pencegahan, Diabetes Melitus

\section{PENDAHULUAN}

Diabetes Melitus merupakan penyakit gangguan metabolik menahun akibat pankreas tidak memproduksi cukup insulin atau tubuh tidak dapat menggunakan insulin yang diproduksi secara efektif (Departemen kesehatan).

Secara global, 422 juta orang didunia menderita diabetes pada tahun 2014 sedangkan pada tahun 1980 penderita diabetes berjumlah 108 juta orang, terjadi peningkatan dari $4,7 \%$ menjadi $8,5 \%$. Peningkatan penyakit diabetes melitus biasanya disebabkan karena adanya faktor resiko seperti peningkatan Berat Badan atau obesitas (World Health Organization, 2016).

Terdapat 415 juta orang yang hidup dengan diabetes melitus pada tahun 2040 jumlah tersebut diperkirakan akan mengalami peningkatan menjadi 642 juta orang. (International Diabetes Federation Atlas 2015).

Peningkatan prevalensi diabetes melitus dari 1,1\% (2007) menjadi 2,1\% (2013). Jumlah penderita Diabetes di Indonesia kian meningkat setiap tahunnya, diabetes dikalangan masyarakat indonesia kebanyakan disebabkan karena gaya hidup dan pola makan yang tidak seimbang. Diabetes Melitus juga 
tidak hanya dialami oleh orang dewasa namun juga remaja bahkan anak-anak. Anak-anak yang mengalami diabetes melitus rata-rata telah mengalami obesitas, meskipun faktor genetik lebih menjadi faktor utama, namun pola makan dan gaya hidup yang tidak sehat juga merupakan faktor penyebab diabetes melitus. (Kemenkes 2013).

Jumlah penduduk pada tahun 2014 yang tercatat di Badan Pusat Statistik (BPS) sebesar 8.432.163 jiwa yang persebarannya tertinggi ditiga kabupaten yaitu, Kota Makassar (16,88\%), Kabupaten Bone $(8,75 \%)$, dan Kabupaten Gowa $(8,41 \%)$. Jumlah penderita diabetes melitus di Sulawesi Selatan berdasarkan gejala sebesar 3,4\%. Prevalensi diabetes tertinggi terdapat di Kabupaten Pinrang (2,8\%), Kota Makassar (2,5\%), Kabupaten Toraja Utara $(2,3 \%)$, dan Kota Palopo $(2,1 \%)$. Prevalensi diabetes berdasarkan gejala tertinggi di Kabupaten Tana Toraja $(6,1 \%)$, Kota Makassar $(5,3 \%)$, Kabupaten Luwu $(5,2 \%)$ dan Kabupaten Luwu Utara (4,0\%). Prevalensi DM pada perempuan cenderung lebih tinggi daripada laki-laki. Prevalensi DM, di Kota cenderung lebih tinggi daripada di pedesaan. Prevalensi DM cenderung lebih tinggi pada masyarakat dengan tingkat pendidikan lebih tinggi. Berdasarkan data survailans penyakit tidak menular Bidang P2PL Dinas Kesehatan Provinsi Sulawesi Selatan tahun 2014 terdapat Diabetes Melitus 27.470 kasus baru, 66.780 kasus lama dengan 747 kematian. (Departemen kesehatan, 2014).

Hasil penelitian Yunanto (2017) disimpulkan bahwa remaja (usia 15-19 tahun) di Kecamatan Kraton memiliki tingkat pengetahuan dan sikap terhadap pola makan dan aktifitas fisik sebagai faktor risiko DM Tipe 2 sudah cukup baik, tetapi masih ditemukan adanya pola makan yang kurang baik pada konsumsi jenis sumber protein, frekuensi konsumsi fast food, frekuensi jenis makanan selingan dan minuman mengandung pemanis. Aktifitas fisik responden sebagian besar berada pada kategori sedang, tetapi masih ditemukan adanya responden yang tidak berolahraga.

Hasil penelitian Indriawati dan Faerus (2009), Prevalensi Obesitas dari tahun cenderung meningkat. Hasil penelitian ini memperlihatkan tidak ada hubungan antara frekuensi konsumsi fast food siswa dengan obesitas. Makanan cepat saji yang dikonsumsi bukan merupakan faktor risiko untuk terjadinya obesitas. Hasil studi Indriawati dan Faerus berbeda dengan yang ditemukan oleh Padmiari, dkk. (2002), yang menyatakan bahwa ada hubungan antara jenis makanan cepat saji yang dikonsumsi dengan kejadian obesitas pada kelompok umur yang berbeda. Tetapi terdapat hubungan antara tingkat aktivitas fisik dengan obesitas siswa SMP. Anak yang memiliki aktifitas fisik tinggi memiliki kecenderungan untuk tidak obesitas daripada anak yang memiliki aktifitas rendah.

Tujuan penelitian Untuk meningkatkan pengetahuan siswa tentang upaya pencegahan diabetes melitus melalui pendidikan kesehatan.

\section{METODE}

Jenis penelitian ini adalah kuantitatif, dengan desain penelitian menggunakan pendekatan Eksperimental, yaitu Eksperimen semu (Quasi eksperimen) seperti pre-post test kelompok intervensi dan kelompok kontrol, dimana rancangannya tergolong dalam rancangan Eksperimen Ulang Non-random (Non Randomized Pretest-Postest with Control Group Design).

Penelitian ini dilaksanakan selama 1 bulan yaitu mulai bulan April sampai bulan Mei 2018 dan Lokasi penelitian di SMA Negeri 1 Gowa dan SMA Negeri 3 Gowa.

Jumlah dan Cara Pengambilan Subjek (Untuk
Penelitian Survei) atau Bahan dan Alat (Untuk
Penelitian Laboratorium)
Populasi dalam penelitian ini yaitu seluruh siswa-siswi SMA Negeri 1 Gowa sebagai kelompok intervensi dan siswa-siswi SMA Negeri 3 Gowa sebagai kelompok kontrol.

Teknik pengambilan sampel dalam penelitian ini menggunakan purposive sampling yakni siswa kelas $X$ MIA 1 yang berjumlah 35 orang siswa pada SMA Negeri 1 Gowa sebagai kelompok intervensi dan siswa kelas X MIA 1 yang berjumlah 35 orang siswa pada SMA Negeri 3 Gowa sebagai kelompok kontrol.

Instrumen penelitian ini menggunakan kuesioner yang berjumlah 15 nomor, digunakan untuk melihat peningkatan pengetahuan pencegahan diabetes melitus pada siswa pre dan post test pada kelompok intervensi melalui tindakan penyuluhan dan pre post test pada kelompok kontrol.

\section{HASIL}

Tabel 1. Karakteristik Umur Menurut Kelompok Subyek (Siswa) Kelas 1 SMA Negeri 1 Gowa dan SMA Negeri 3 Gowa

\begin{tabular}{llllll}
\hline \hline Kelompok & Frekuensi & Minimum & Maksimum & Mean & SD \\
\hline Intervensi & 33 & 14 & 17 & 15,45 & 0,66 \\
\hline Kontrol & 33 & 15 & 17 & 15,48 & 0,56 \\
\hline
\end{tabular}

Sumber: Data Primer Hasil survey Siswa Kleas 1 SMAN 1 Gowa dan SMAN 3 Gowa 
Memperhatikan karakteristik umur siswa SMA Negeri 1 Gowa dan SMA Negeri 3 Gowa yang menjadi subyek penelitian ini terlihat dengan variasi yang cukup homogen. Rata-rata umur kedua kelompok tersebut yakni pada kelompok intervensi 15,45 tahun dengan setandar deviasi 0,66 atau dengan interval umur antara $14-17$ tahun, umur termuda 14 tahun dan tertua umur 17 tahun, berbeda dengan kelompok kontrol dengan rata-rata umur 15,48 tahun atau rata-rata interval 15 - 17 tahun, termuda 15 tahun dan tertua 17 tahun, sehingga terkesan kelompok intervensi cenderung lebih muda dibandingkan dengan kelompok kontrol, sekalipun secara klasikal keduanya adalah individu pada kelas yang sama di SMAN Gowa.

Tabel 2. Karakteristik Jenis Kelamin Menurut Kelompok Subyek (Siswa) Kelas 1 SMA Negeri 1 Gowa dan SMA Negeri 3 Gowa

\begin{tabular}{|l|l|l|l|l|l|l|}
\hline \hline \multirow{2}{*}{$\begin{array}{l}\text { Jenis } \\
\text { Kelamin }\end{array}$} & \multicolumn{3}{|l|}{ Kelompok Subyek } & \multicolumn{2}{l|}{ Jumlah } \\
\cline { 2 - 7 } & Intervensi & \multicolumn{2}{|l|}{ Kontrol } & \multicolumn{2}{l|}{} \\
\cline { 2 - 7 } & $\mathrm{n}$ & $\%$ & $\mathrm{n}$ & $\%$ & $\mathrm{n}$ & $\%$ \\
\hline Laki-laki & 8 & 40,0 & 12 & 60,0 & 20 & 100 \\
Perempuan & 25 & 54,3 & 21 & 45,7 & 46 & 100 \\
\hline & 33 & 50,0 & 33 & 50,0 & 66 & 100 \\
\hline
\end{tabular}

Sumber: Data Primer Hasil survey Siswa Kleas 1 SMAN 1 Gowa dan SMAN 3 Gowa

Data tentang karakteristik jenis kelamin pada tabel 2 terlihat bervariasi antara kedua kelompok intervensi dan kelompok kontrol, secara keseluruhan lebih banyak perempuan yakni 46 dengan jumlah terbanyak pada kelompok intervensi sebesar 25 siswa $(54,3 \%)$ dibandingkan dengan jenis kelamin yang sama pada kelompok kontrol sebesar 21 siswa $(45,7 \%)$, berbanding terbalik pada jenis kelamin perempuan, laki-laki lebih banyak pada kelompok kontrol sebesar 12 siswa (60\%) dibandingkan dengan kelompok intervensi 8 siswa (40\%).

Tabel 3. Karakteristik Tingkat Pengetahuan Subyek (Siswa) Kelas 1 SMA Negeri 1 Gowa dan SMA Negeri 3 Gowa Pre Intervensi

\begin{tabular}{|l|l|l|l|l|l|l|}
\hline \hline \multirow{2}{*}{$\begin{array}{l}\text { Kelompok } \\
\text { Subyek }\end{array}$} & \multicolumn{4}{|l|}{ Pengetahuan } & \multicolumn{2}{l|}{ Jumlah } \\
\cline { 2 - 7 } & \multicolumn{2}{|l|}{ Baik } & \multicolumn{2}{l|}{ Kurang } & \multicolumn{2}{l|}{} \\
\cline { 2 - 7 } & $\mathrm{n}$ & $\%$ & $\mathrm{~N}$ & $\%$ & $\mathrm{n}$ & $\%$ \\
\hline Intervensi & 12 & 36,4 & 21 & 63,6 & 33 & 100 \\
Kontrol & 10 & 30,3 & 23 & 69,7 & 33 & 100 \\
\hline Jumlah & 22 & 33,3 & 44 & 66,7 & 66 & 100 \\
\hline
\end{tabular}

Sumber: Data Primer Hasil survey Siswa Kleas 1 SMAN 1 Gowa dan SMAN 3 Gowa
Data pada tabel 3 di atas secara deskriptif tentang tingkat pengetahuan subyek sebelum pelaksanaan intervensi dalam berbagai upaya pencegahan terlihat pada kelompok intervensi terdapat 12 siswa $(36,4 \%)$ yang memiliki pengetahuan baik, sedikit lebih tinggi dari kelompok kontrol yakni 10 siswa $(30,3 \%)$, sementara 21 siswa $(63,6 \%)$ pada kelompok intervensi dan 23 siswa $(69,7 \%)$ dari kelompok kontrol dengan pengetahuan kurang.

Tabel 4. Karakteristik Tingkat Pengetahuan Subyek (Siswa) Kelas 1 SMA Negeri 1 Gowa dan SMA Negeri 3 Gowa Post Intervensi

\begin{tabular}{|l|l|l|l|l|l|l|}
\hline \hline \multirow{2}{*}{$\begin{array}{l}\text { Kelompok } \\
\text { Subyek }\end{array}$} & \multicolumn{3}{|l|}{ Pengetahuan } & \multicolumn{2}{l|}{ Jumlah } \\
\cline { 2 - 7 } & \multicolumn{2}{|l|}{ Baik } & \multicolumn{2}{l|}{ Kurang } & \multicolumn{2}{l|}{} \\
\cline { 2 - 7 } & $\mathrm{N}$ & $\%$ & $\mathrm{~N}$ & $\%$ & $\mathrm{n}$ & $\%$ \\
\hline $\begin{array}{l}\text { Intervensi } \\
\text { Kontrol }\end{array}$ & 28 & 84,8 & 5 & 15,2 & 33 & 100 \\
\hline Jumlah & 6 & 18,2 & 27 & 81,8 & 33 & 100 \\
\hline
\end{tabular}

Sumber: Data Primer Hasil survey Siswa Kelas 1 SMAN 1 Gowa dan SMAN 3 Gowa

Terlihat pada tabel 4 di atas adanya perubahan penigkatan pengetahuan dengan katagori baik menjadi 28 siswa $(84,8 \%)$ untuk kelompok intervensi, berbeda dengan kelompok kontrol yang justru terjadi penurunan untuk pengetahuan yang baik menjadi 6 siswa $(18,2 \%)$, sementara 5 siswa $(15,2 \%)$ dari kelompok intervensi dengan katagori tingkat pengetahuan kurang, jauh lebih kecil dibandingkan dengan 27 siswa $(81,8 \%)$ dari kelompok kontrol. 
Tabel 5. Analisis Pengaruh Upaya Pencegahan Dini DM terhadap Tingkat Pengetahuan Siswa SMA Negeri 1 Gowa Kelompok Intervensi

\begin{tabular}{|c|c|c|c|c|c|c|c|}
\hline \multirow{3}{*}{ Pre - Intervensi } & \multicolumn{4}{|c|}{ Post - Intervensi } & \multirow{2}{*}{\multicolumn{2}{|c|}{ Jumlah }} & \multirow{3}{*}{$\begin{array}{l}\text { Hasil Uji Mc - } \\
\text { Nemar } \\
\text { (alpha }=0,05)\end{array}$} \\
\hline & \multicolumn{2}{|c|}{ Baik } & \multicolumn{2}{|c|}{ Kurang } & & & \\
\hline & $\mathrm{N}$ & $\%$ & $\mathrm{~N}$ & $\%$ & $\mathrm{~N}$ & $\%$ & \\
\hline Baik & 12 & 100,0 & 0 & 0,0 & 12 & 100 & p. value $(0,000)$ \\
\hline Kurang & 16 & 76,2 & 5 & 23,8 & 21 & 100 & \\
\hline Jumlah & 28 & 84,8 & 5 & 15,2 & 33 & 100 & \\
\hline
\end{tabular}

Sumber: Data Primer Hasil survey Siswa Kelas 1 SMAN 1 Gowa Dan SMA 3 Gowa

Data pada tabel 5 menunjukkan bahwa dari 33 siswa SMAN 1 Gowa yang merupakan kelompok intervensi di antaranya terdapat 12 siswa sebelum intervensi memiliki tingkat pengetahuan baik, semuanya $(100 \%)$ tetap memiliki pengetahuan yang baik, sementara dari 21 siswa sebelum intervensi memiliki pengetahuan yang kurang, ternyata setelah intervensi tentang upaya pencegahan dini DM 5 siswa $(23,8 \%)$ yang pengetahuannya kurang, sedangkan $16 \quad(76,2 \%)$ siswa mengalami peningkatan pengetahuan dari kurang menjadi baik

Tabel 6. Analisis Pengaruh Upaya Pencegahan Dini DM terhadap Tingkat Pengetahuan Siswa SMA Negeri 3 Gowa Kelompok Kontrol

\begin{tabular}{|c|c|c|c|c|c|c|c|}
\hline \multirow{3}{*}{ Pre - Intervensi } & \multicolumn{4}{|c|}{ Post - Intervensi } & \multirow{2}{*}{\multicolumn{2}{|c|}{ Jumlah }} & \multirow{3}{*}{$\begin{array}{l}\text { Hasil Uji Mc - } \\
\text { Nemar } \\
\text { (alpha }=0,05)\end{array}$} \\
\hline & \multicolumn{2}{|c|}{ Baik } & \multicolumn{2}{|c|}{ Kurang } & & & \\
\hline & $\mathrm{N}$ & $\%$ & $\mathrm{~N}$ & $\%$ & $\mathrm{~N}$ & $\%$ & \\
\hline $\begin{array}{l}\text { Baik } \\
\text { Kurang }\end{array}$ & $\begin{array}{l}6 \\
0\end{array}$ & $\begin{array}{l}60,0 \\
0,0\end{array}$ & $\begin{array}{l}4 \\
23\end{array}$ & $\begin{array}{l}40,0 \\
100,0\end{array}$ & $\begin{array}{l}10 \\
23\end{array}$ & $\begin{array}{l}100 \\
100\end{array}$ & p. value $(0,125)$ \\
\hline Jumlah & 6 & 18,2 & 27 & 81,2 & 33 & 100 & \\
\hline
\end{tabular}

Sumber: Data Primer Hasil survey Siswa Kelas I SMAN 3 Gowa

Hasil analisis dengan Uji Mc-Nemar pada $\mathrm{CL}=0,95$ diperoleh nilai Exact Sig untuk dua sisi sebesar 0,125 $>a=0,05$ menunjukkan bahwa secara statistic disimpulkan untuk menerima Ho yang berarti bahwa tidak terdapat perbedaan tingkat pengetahuan siswa yang tidak diberikan intervensi, dengan kata lain tidak terdapat pengaruh yang signifikan upaya pencegahan dini DM terhadap peningkatan pengetahuan siswa SMAN 3 Kabupaten Gowa pada kelompok kontrol. terdahulu menunjukkan bahwa 33 siswa yang terpilih menjadi sampel untuk kelompok kontrol, terdapat 10 siswa yang memiliki pengetahuan yang berkatagori baik, 6 siswa (60\%) diataranya yang tetap dengan pengetahuan baik, sedangkan 4 siswa $(40,0 \%)$ yang pengetahuannya berubah dari baik menjadi kurang. Sementara dari 23 siswa dengan pengetahuan kurang ternyata tetap dengan pengetahuan kurang. setelah intervensi. Hasil uji hipotesis dengan MCnemar pada tingkat kepercayaan (CL.0,95) di peroleh
nilai Exact Sig untuk dua sisi sebesar $0,000<\alpha=$ terdapat perbedaan tingkat pengetahuan siswa dari sebelum dan sesudah dilakukan intervensi, dengan pencegahan dini DM terhadap peningkatan pengetahuan siswa SMAN 1 Kabupaten Gowa.

Tabel 4.7. Analisis Pengaruh Upaya Pencegahan Dini DM terhadap Tingkat Pengetahuan Siswa SMA Negeri I Gowa dan SMA Negeri 3 Gowa

\begin{tabular}{|c|c|c|c|c|c|c|}
\hline \multirow{2}{*}{$\begin{array}{c}\text { Upaya } \\
\text { Pencegahan }\end{array}$} & Intervensi & Kontrol & \multicolumn{4}{|c|}{ Mann-Whitney Test } \\
\cline { 2 - 7 } & Mean Rank & $\begin{array}{c}\text { Mean } \\
\text { Rank }\end{array}$ & U & W & Z & $\begin{array}{c}\text { p.value ( } \alpha \\
=0,05)\end{array}$ \\
\hline Pre-test & 38,77 & 26,23 & 370,50 & 931,50 & $-2,26$ & 0,024 \\
\hline Post-Test & 46,24 & 20,76 & 124,00 & 585,00 & $-5,423$ & 0,000 \\
\hline
\end{tabular}

Sumber: Data Primer Hasil survey Siswa Kelas 1 SMAN 1 Gowa dan SMAN 3 Gowa 
Hasil analisis pada tabel 7 dalam uji Mann whitney menunjukkan bahwa nilai mean rank atau rerata peringkat pengetahuan siswa yang terpilih menjadi sampel dalam upaya pencegahan dalam pre-test lebih tinggi pada kelompok intervensi dibandingkan dengan kelompok kontrol $(38,77>$ 26 ,23). Pada uji statistic menggunakan Mann whitney (U) sebesar 370,50 dan nilai W sebesar 931,50, jika dikonversi ke nilai $Z$ didapatkan nilai yang kecil ($2,26)$ dengan $p$. value $(0,024<0,05)$ menunjukkan bahwa terdapat perbedaan yang signifikan tingkat pengetahuan siswa dalam upaya pencegahan pada pre-test. Analisis lanjut yang dilakukan pada upaya pencegahan post-test menunjukkan bahwa nilai mean pengetahuan siswa yang mendapatkan perlakuan dalam upaya pencegahan dini DM lebih besar dibandingkan dengan nilai mean pengetahuan siswa siswa yang tidak mendapatkan perlakuan $(46,24>20,76)$, sebagai dasar pembuktian apakah perbedaan tersebut cukup bermakna atau signifikan dari hasil uji statistik didapatkan nilai Mann-Withney (U) sebesar 124,00 , dan nilai $W=585,00$, yang apabila dikonversi ke nilai $Z$ terdapat $-5,423$ dan nilai p untuk 2 sisi sebesar $0,000<0,05$ yang menunjukkan bahwa terdapat perbedaan yang signifikan tingkat pengetahuan siswa antara mereka yang mendapatkan intervensi tentang upaya pencegahan dini penyakit Diabetes Mellitus, Karena itu secara statistic dapat disimpulkan bahwa terdapat pengaruh yang signifikan upaya pencegahan Dini DM pada siswa SMA terhadap peningkatan pengetahuan mereka, dengan kata lain bahwa siswa SMA kelas satu yang mendapatkan intervensi secara memadai akan meningkatkan pengetahuan mereka secara memadai.

\section{PEMBAHASAN}

Hasil uji hipotesis dengan MC-nemar menunjukkan bahwa terdapat pengaruh secara signifikan tentang upaya pencegahan dini terhadap peningkatan pengetahuan siswa SMAN 1 Gowa yang menjadi sampel dalam penelitian ini. Hal itu dibuktikan dengan adanya perbedaan tingkat pengetahuan siswa antara sebelum dan sesudah intervensi. Berbanding terbalik dengan siswa SMAN 3 Gowa sebagai kelompok control yang menunjukkan tidak adanya perbedaan yang signifikan upaya pencegahan terhadap pengetahuan siswa. Kenyataan tersbut menunjukkan bahwa siswa yang mendapatkan informasi yang cukup (perlakuan seperti penyuluhan) tentang pencegahan DM akan menjadi dasar bagi mereka untuk melakukan pencegahan.

Pengetahuan tentang pencegahan suatu penyakit khususnya tentang DM sangat berpengaruh terhadap perilaku pencegahan diabetes mellitus. Karena menurut pendapat Notoatmodjo (2003), pengetahuan merupakan hasil dari tahu dan ini terjadi setelah orang melakukan penginderaan terhadap suatu obyek tertentu. Pengetahuan masyarakat yang kurang tentang penyakit diabetes mellitus dapat berpengaruh pada tingkat kesadaran yang rendah, sehingga deteksi dini penyakit tersebut tidak dapat diketahui yang pada gilirannya akan berakibat terjadinya penyakit tersebut yang akhirnya terjadi komplikasi berlanjut. Sebaliknya apabila pengetahuan masyarakat baik tentang penyakit diabetes mellitus dapat berpengaruh pada tingkat kesadaran yang baik pula. Sehingga deteksi dini dari gejala yang ditimbulkan akan diketahui. Deteksi dini diabetes mellitus adalah tindakan awal sebagai upaya kemungkinan terkena diabetes mellitus secara dini agar dapat ditangani secara memadai, sehingga kesakitan atau komplikasi dapat dicegah.

Hasil penelitian ini sesuai dengan penelitian yang dilakukan Bart (1994 dalam Notoadmodjo, 2003), yang menyatakan bahwa perilaku yang dilakukan atas dasar pengetahuan akan lebih bertahan dari pada perilaku yang tidak didasari oleh pengetahuan. Karena itu pengetahuan sangat dibutuhkan agar masyarakat dapat lebih mudah untuk diubah kearah yang lebih baik terutama bagi mefeka di usia yang masih sangat muda, seperti mereka yang masih duduk dibangku SMA dan sederajat.

Pengetahuan adalah hasil "tahu" dan ini terjadi setelah orang mengadakan penginderaan terhadap suatu objek tertentu. Penginderaan terhadap objek terjadi melalui panca indra manusia yakni penglihatan, pendengaran, penciuman, rasa dan raba dengan sendiri. Pada waktu pengindraan sampai menghasilkan pengetahuan tersebut sangat dipengaruhi oleh intensitas perhatian persepsi terhadap obyek (Notoatmodjo, 2003).

Sebagian besar pengetahuan manusia diperoleh melalui pendidikan, pengalaman sendiri maupun pengalaman yang didapat dari orang lain, sehingga pengetahuan sangat penting untuk membentuk perilaku seseorang (Notoatmodjo, 2003). Begitu pula halnya dalam melakukan pencegahan terhadap penyakit diabetes mellitus memerlukan pengetahuan yang memadai.

Hal tersebut dapat dipahami karena dalam upaya pencegahan dengan lima tingkatan di mana peningkatan pengetahuan menjadi bagian dari upaya promotif-preventif sangat relevan untuk dikembangkan terutama dalam upaya pencegahan dini penyakit Diabetes Mellitus sebagai upaya pencegahan primordial, sehingga mereka yang memiliki potensi atau bakat untuk mengalami penyakit tersebut dapat mereka lakukan upaya pencegahan, disisi lain dalam upaya untuk mengembangkan pengetahuan tersebut di tingkat keluarga bahkan di masyarakat luas, mengingat bahwa prevalensi penderita penyakit Diabetes Mellitus yang berkembang di masyarakat sangat 
tinggi seiring dengan meningkatnya kondisi social masyarakat.

\section{KESIMPULAN}

1. Upaya pencegahan dini Diabetes Mellitus (DM) berpengaruh secara signifikan terhadap peningkatan pengetahuan Siswa SMAN 1 Gowa, jika pengetahuan siswa meningkat terhaadap pencegahan dini penyakit Diabetes Mellitus (DM). Hal ini akan berdampak positif pula terhadap sosialisasi upaya pencegahan dalam meningkatkan pengetahuan ditingkat keluarga dan masyarakat.

2. Terdapat perbedaan tingkat pengetahuan siswa antara mereka yang mendapat perlakukan dengan siswa tanpa perlakuan.

3. Terjadi peningkatan pengetahuan siswa tentang faktor penyebab terjadinya penyakit Diabetes Melitus (DM) setelah diberi penyuluhan dengan metode ceramah dan Tanya jawab.
4. Terjadi peningkatan pengetahuan siswa mengenai gaya hidup yang sehat setelah diberi penyuluhan dengan metode ceramah dan tanya jawab.

5. Terjadi peningkatan pengetahuan siswa mengenai pola makan yang baik setelah diberi penyuluhan dengan metode ceramah dan tanya jawab.

\section{SARAN}

1. Perlunya sosialisasi upaya pencegahan penyakit Diabetes Mellitus ditingkat Sekolah Menengah Atas yang ada dengan memasukkan program pendidikan upaya pencegahan dalam kurikulum sekolah.

2. Diperlukan partisipasi siswa SMA dalam menyebarluaskan upaya pencegahan dini penyakit DM di lingkungan Sekolah, keluarga dan masyarakat secara umum.

3. Perlu penelitian secara khusus tentang upaya pencegahan dini bagi kelompok risiko tinggi penyakit DM.

\section{DAFTAR PUSTAKA}

Dinas Kesehatan Provinsi Sulawesi Selatan (Depkes). (2014). http://www.depkes.go.id/resources/download/profil/PROFIL_KES_PROVINSI_2014/27_Sulawesi_Selatan_201 4.pdf diakes, 14 Februari 2018, Pukul 16:00.

Hurlock, dkk. (2012). Psikologi Perkembangan. Jakarta: Erlangga.

Indriawati, Faerus. (2009). Hubungan Konsumsi Makanan Cepat Saji dan Tingkat Aktifitas Fisik Terhadap Obesitas Pada Kelompok Usia 11-13 Tahun. https://www. ID-hubungan-konsumsi-makanan-cepat-sajidan.pdf\&usg=AOvVawOwYPkGvEAypgOT-v9JrVkG diakses, 28 Januari 2018, Pukul 21:00.

International Diabetes Federation Atlas (IDF). (2015). http://www.oedg.at/pdf/1606 IDF_Atlas_2015_UK.pdf diakses, 14 Februari 2018, Pukul 14:30.

Noor, Nur Nasri. (2014). Epidemiologi. Jakarta: PT Rineka Cipta

Notoatmodjo, Soekidjo. (2012). Metodologi Penelitian Kesehatan. Jakarta: PT Rineka Cipta

Nuari, N.A, dkk. (2017). Strategi Manajemen Edukasi Pasien Diabetes Melitus. Yogyakarta: CV Budi Utama

Riset Kesehatan Dasar (Riskesdas). (2013). http://www.depkes.go.id/resources/download/general/Hasil\%20Riskesdas\%202013 diakses, 14 Februari 2018, Pukul 15:00

Rumahorbo, Hotma. (2014). Mencegah Diabetes Melitus Dengan Perubahan Gaya Hidup. Bogor: In Media

Saryono, dkk. (2017). Metodologi Penelitian Kualitatif Dan Kuantitatif Dalam Bidang Kesehatan. Yogyakarta: Nuha Medika

Soedarsono. (2016). Cara Alami Mencegah Dan Mengobati Diabetes. Surabaya: Stomata

Tarwoto, dkk. (2016). Keperawatan Medikal Bedah Gangguan Sistem Endokrin. Jakarta Timur: CV. Trans Info Media

Wawan, dkk. (2011). Teori Dan Pengukuran Pengetahuan, Sikap, Dan Perilaku Manusia. Yogyakarta: Nuha Medika

World Health Oraganization (WHO). (2016). http://apps.who.int/iris/bitstream/10665/204871/1/9789241565257_eng.pdf diakses, 14 Februari 2018, Pukul 14.30.

Yunanto. (2017). Pengetahuan, Sikap dan Tindakan Terhadap Pola Hidup Terkait Risiko Diabetes Melitus Tipe 2 Pada Remaja Di Kecamatan Kraton Yogyakarta. Repository.usd.ac.id 